\title{
Sorption Properties of a Bentonite Based Material for Removal of Uranium from Alum Shale Leachate
}

\author{
Emilio Alvarenga ${ }^{1}$, Sergey Hayrapetyan ${ }^{2}$, Lindis Skipperud $^{3}$, Lusine Hayrapetyan $^{2}$, Marte Linjordet ${ }^{4}$ and Brit Salbu ${ }^{3}$ \\ 1. Norwegian Institute of Bioeconomy Research, NIBIO, Frederik A. Dahls vei 20, NO-1430 As, Norway \\ 2. Yerevan State University, A. Manoogyan St. 1 0025, Yerevan, Armenia \\ 3. Dept. of Env. Sci., NMBU (Norwegian University of Life Sciences), NO-1432, As, Norway \\ 4. Dept. of Chem., Biotech. and Food Sci., NMBU (Norwegian University of Life Sciences), NO-1432, As, Norway
}

\begin{abstract}
A dynamic sorption experiment was performed for removal of uranium (VI or 6+) from a leachate from an alum shale landfill with a diatomite-bentonite based sorbent in a laboratory scale. Such material was grounded and treated chemically with $\mathrm{H}_{3} \mathrm{PO}_{4}$ (phosphoric acid) and thermally for improving its porosity and resistance to water flow. A specific surface area of $209 \mathrm{~m}^{2} \cdot \mathrm{g}^{-1}$ was determined by the BET method. A sorption capacity of $30 \mu \mathrm{g} \cdot \mathrm{g}^{-1}$ and $0.6 \mu \mathrm{g} \cdot \mathrm{g}^{-1}$ was obtained at a $\mathrm{pH}$ of 7.5 and 4 respectively by means of Langmuir and Freundlich isotherm models. The flow rate of $3 \mathrm{~mL} \cdot \mathrm{min}^{-1}$ was effective for controlling the $\mathrm{pH}$ inside of the column. The sorption mechanism was investigated along with desorption of the element of interest for further process design considerations for a treatment unit on the landfill site.
\end{abstract}

Key words: Clay based sorbents, sorption of uranium, langmuir and freundlich adsorption models, adsorption capacity.

\section{Introduction}

Exploitation and/or disturbance of natural reserves of $U$ (Uranium) in Norway, as shale deposits from the Cambrian era could release significant amounts of radionuclides to the environment during and after closing of such operations as mining or all kinds of man-made disturbances. Alum shale rocks are unevenly distributed in the country and are particularly abundant in Oslo region [1]. Usually, $\mathrm{U}$ is present in the environment in hexavalent form as $\mathrm{UO}_{2}{ }^{2+}$ and it threatens aquatic life and human health due to its mobilization along with other radionuclides (Rn-222, Po-218 and Po-214), heavy metals (Fe, $\mathrm{Cu}$, $\mathrm{Zn}, \mathrm{Ni}, \mathrm{Cd}, \mathrm{Pb}$ and $\mathrm{Mn}$ ), trace elements and salts of $\mathrm{Na}$ and $\mathrm{K}$ [2-7]. On the other hand, urbanization and the development of highway infrastructures as railways, roads, bridges and tunnels can contribute further to such environmental impact. An environmental impact assessment during and after the

Corresponding author: Emilio Alvarenga, M.Sc. (tech.), research field: environmental chemistry (wastewater treatment). completion of mining or construction projects is hence required.

Uncontrolled deposits of alum shale material with a high pyrite $\left(\mathrm{FeS}_{2}\right)$ content undergo weathering where sulfides are oxidized to sulfate [2]. A further hydrolysis of the sulphates dissolves a large number of heavy metals, radionuclides and trace elements. In other words, these contaminants are being leached from the solid phases in different weather conditions and rainfall and these become mobile. Under very acidic conditions $(\mathrm{pH}<3)$, metal content (heavy metals, radionuclides or trace elements) is greatly increased in the acid streams or leachate. The leachate, which also releases metals, increases thereby their content in aqueous systems. In addition, trace elements may be present in various forms, from molecular dissolved state to colloidal sizes and micron-sized particles. Among these inorganic pollutants, $U$ and its decay products could have high concentrations in the mineral due to its heterogeneity and these could potentially be mobilized to ground- and surface water bodies. Furthermore, other inorganic pollutants could be present 
in leachates in trace levels or higher concentrations.

Liming or natural calcium carbonate in the ores, delays the hydrolysis of $\mathrm{S}^{2-}$ and further solubility of cations [3]. However, the environmental issue is temporarily solved due to possible remobilization of the ionic pollutants under oxic conditions. Separation processes from liquid to solid are therefore getting relevance for the treatment of leachates from landfills or mining tails as significant amounts of water can be treated in order to reach legislation thresholds for discharges. Some of the water contaminants are $\mathrm{Ca}$, $\mathrm{Mg}, \mathrm{K}, \mathrm{Fe}, \mathrm{Cu}, \mathrm{Zn}, \mathrm{Ni}, \mathrm{Cd}, \mathrm{Pb}$ and $\mathrm{Mn}[1,4]$ and radionuclides U-238 and daughters like $\mathrm{Ra}-226$, Po-210, Pb-210. There are many alternatives for the treatment of such wastewater streams. The primary methods for heavy metals removal are (1) reagent, (2) membrane, (3) electrochemical, (4) biochemical and (5) sorption methods. Several alternatives have already been investigated for $\mathrm{U}^{6+}$, among them co-precipitation, membrane filtration and sorption [9-11].

Other methods as ion exchange and electrochemical ones have several disadvantages. Among them, large amounts of heavy metal solutions are formed during the ion exchange by removing pollutants of interest but releasing simultaneously other heavy metals to the water phase. Electrochemical methods along with membrane filtration are energy intensive on the other hand.

The most common and effective method is sorption. The advantage of this method is that it is possible to purify wastewater, which contains large amounts of impurities (e.g. either organic or inorganic). Effectiveness of water treated by this method may rise up to $80-95 \%$, depending on the chemical nature of the sorbents, their structure and size of the adsorption surface. In recent years, attention has been given to natural sorbents or sorbents obtained based on materials of natural origin for water treatment. The most interesting are fibrous filled sorbents, ferrocyanides of transition metals and titanium compounds. They have been successfully used for radionuclide separation [5-9]. Furthermore, it is possible to combine a pretreatment of the effluent either by a process sequence with $\mathrm{pH}$ adjustment, chemical precipitation, coagulation/flocculation and sorption of dissolved pollutants as a last step to increase the separation efficiency.

Sorption processes represent a feasible alternative as well due to multiple regenerations of the sorbents with strong acids and use of natural abundant materials as apatites, clays and other silica-containing systems which have porosity and functional groups for physical/chemical binding of pollutants in solution [10-12]. In order to increase the efficiency of separation, it is necessary to create new types of sorbents, which have a maximum selectivity towards specific elements.

There are porous materials available from which it is possible to produce effective sorbents. Many natural minerals (e.g. zeolites, clay, clinoptilollite, mordenite, tuffs) have such advantage and for this reason, they have widely been studied [13-16]. However, these materials require chemical and/or physical treatments to become effective sorbents. Moreover, selectivity is among the greatest challenges in these naturals minerals. Among these, the most widely used methods are acid and alkali treatment, hydrothermal and thermal treatment, mechanical activation and pillaring. However, there is a knowledge gap for improving selectivity and removal capacity for $U$ species in water. There are not natural sorbents with a high efficacy that could become an alternative to the expensive titanium dioxide sorbents. The sorption of $\mathrm{U}^{6+}$ has been investigated in clays as montmorillonites and smectites [17] and other types of materials as zeolites [18] and granites [19] have been studied as well. In addition, olivines have $-\mathrm{OH}$ functional groups that complexate $\mathrm{UO}_{2}{ }^{2+}$ in the surface as shown by El Aamrani et al. [20]. In the last few years, it has been suggested to impregnate chemically the carrier or surface of the sorbent, which shows selectivity for the ion, or ions, of interest. The carrier might be an ion-exchange resin, cellulose, actived carbon or natural minerals. The 
application of this method resulted hence, in the development of several new sorbents [21, 22].

Challenges are encountered additionally in sorption processes concerning the affinity to remove $\mathrm{U}^{6+}$ in multiphase systems. The latter are commonly found in the environment. Competition for sorption sites is thus enhanced and does have an impact in the $\mathrm{U}^{6+}$ removal capacity. Such effects could be attributed to anions (carbonates and phosphates) [23-26], cations (e.g. $\mathrm{Ba}^{2+}, \mathrm{Ca}^{2+}$ and $\left.\mathrm{K}^{+}\right)[27,28]$ and humic substances [29, 30]. Moreover, high concentrations of both anions and cations could either increase or decrease the sorption of $\mathrm{U}^{6+}$ by forming stable species of $\mathrm{U}$ as calcium-uranyl-carbonate-complex or anion-cation-surface ternary complexes. Therefore, there are expected changes in both the surface and the species of $U$ in solution where $\mathrm{pH}$ in the solution plays an important role concerning the speciation. Furthermore, organic complexation over the surface of the sorbent could have or not an effect on the separation as investigated by Logue et al. [29] and Křepelová et al. [30]. The former investigation revealed that the $\mathrm{U}^{6+}$ removal was reduced by $50 \%$ by means of an iron sand system when citrate was present in solution. The latter study showed how $\mathrm{U}^{6+}$ "preferred" to sorb to kaolinite and not to humic acid that was directly bound to a clay surface [30].

The upscaling of the removal of $\mathrm{U}^{6+}$ by sorption, can be investigated in static or dynamic mode [10]. In the latter, binders are required to avoid permeability problems associated to flow rate $(Q)$ in the columns. The flow resistance of a granulated sorbent is a challenge for up-scaling.

The aim of this work is to study the sorption of $\mathrm{U}^{6+}$ (naturally present in alum shale) in dynamic mode with a bentonite based material in a laboratory scale. The wastewater effluent was a leachate sampled from an alum shale landfill. Treatment of the natural materials was carried out for binding or granulating the sorbents to enhance mass transfer through their porous structure as well as for avoiding permeability problems in the columns.

\section{Materials and Methods}

\subsection{Leachate}

The leachate was sampled in the spring 2015 from a superficial water of an open alum shale landfill. The latter was constructed under the Norwegian Public Roads Administration (Statens Vegvesen) standards. It was located by the construction site of a road (RV4) and a tunnel in Gran County, Norway. The physicochemical parameters of the leachate were analyzed in accordance to the standard methods for examination of water and wastewater and can be seen from Table 1 [31]. The sample was stored at $4{ }^{\circ} \mathrm{C}$ prior to the start of the sorption experiments.

\subsection{Sorbents Preparation and Characterization}

\subsubsection{Diatomite-Bentonite Sorbent}

The sorbent coded as DB-12P-HP was prepared in a laboratory scale. Its chemical composition of the base materials was determined by XRF (fluorescence x-ray spectrometry) from scanning electron microscopy and it can be seen from Table 2. The base materials are a bentonite produced by the Ijevan Bentonite Company and a diatomite elaborated by the Diatomite Company, both from the Republic of Armenia. The code "DB" refers to the diatomite-bentonite combined system. A $1 \mathrm{~L}$ bentonite slurry of $200 \mathrm{~g} \cdot \mathrm{L}^{-1}$ was prepared and mixed with $100 \mathrm{ml}$ of a $10 \% \%_{\mathrm{v} / \mathrm{v}}$ solution of phosphoric acid $\left(\mathrm{H}_{3} \mathrm{PO}_{4}\right)$. The volume ratio of bentonite to $\mathrm{H}_{3} \mathrm{PO}_{4}$ was 10:1. The mixture was left in contact and undisturbed overnight. Afterward, a $0.5 \mathrm{~L}$ slurry of diatomite of $200 \mathrm{~g} \cdot \mathrm{L}^{-1}$ was added to the aforementioned mixture. The code "12P" refers to the DB weight ratio of Bentonite:Diatomite $=2: 1$. The system was then filtered and the resulting cake was dried at room temperature; followed by a drying at $105{ }^{\circ} \mathrm{C}$. The system was grounded in order to obtain a homogeneous powder consistency. The term "HP" refers to a further treatment with $\mathrm{H}_{3} \mathrm{PO}_{4}$. 
Table 1 Physicochemical parameters of the leachate.

\begin{tabular}{|c|c|c|}
\hline Parameter & Unit & $\begin{array}{l}\text { Value or } \\
\text { concentration }\end{array}$ \\
\hline $\mathrm{pH}\left(25^{\circ} \mathrm{C}\right)$ & - & 7.5 \\
\hline TOC* & $\mathrm{mg} \cdot \mathrm{L}^{-1}$ & 1.2 \\
\hline Alkalinity $(\mathrm{pH}=8.3)$ & $\mathrm{mmol} \cdot \mathrm{L}^{-1}$ & $<0.15$ \\
\hline Turbidity & FNU & 26.4 \\
\hline Suspended solids & $\mathrm{mg} \cdot \mathrm{L}^{-1}$ & 26.1 \\
\hline S & $\mathrm{mg} \cdot \mathrm{L}^{-1}$ & 116 \\
\hline $\mathrm{SO}_{4}{ }^{2-}$ & $\mathrm{mg} \cdot \mathrm{L}^{-1}$ & 309 \\
\hline $\mathrm{N}_{\text {total }}$ & $\mathrm{mg} \cdot \mathrm{L}^{-1}$ & 27.5 \\
\hline $\mathrm{P}_{\text {total }}$ & $\mathrm{mg} \cdot \mathrm{L}^{-1}$ & 0.03 \\
\hline Cl- & $\mathrm{mg} \cdot \mathrm{L}^{-1}$ & 25.4 \\
\hline $\mathrm{Ca}$ & $\mathrm{mg} \cdot \mathrm{L}^{-1}$ & 110 \\
\hline $\mathrm{Fe}$ & $\mu \mathrm{g} \cdot \mathrm{L}^{-1}$ & 327 \\
\hline K & $\mathrm{mg} \cdot \mathrm{L}^{-1}$ & 12.2 \\
\hline $\mathrm{Mg}$ & $\mathrm{mg} \cdot \mathrm{L}^{-1}$ & 14 \\
\hline $\mathrm{Na}$ & $\mathrm{mg} \cdot \mathrm{L}^{-1}$ & 110 \\
\hline $\mathrm{Al}$ & $\mu \mathrm{g} \cdot \mathrm{L}^{-1}$ & 213 \\
\hline As & $\mu g \cdot L^{-1}$ & 5.35 \\
\hline $\mathrm{Ba}$ & $\mu \mathrm{g} \cdot \mathrm{L}^{-1}$ & 140 \\
\hline $\mathrm{Cd}$ & $\mu \mathrm{g} \cdot \mathrm{L}^{-1}$ & 0.50 \\
\hline Co & $\mu g \cdot L^{-1}$ & 0.33 \\
\hline $\mathrm{Cr}$ & $\mu \mathrm{g} \cdot \mathrm{L}^{-1}$ & 0.23 \\
\hline Cs & $\mu \mathrm{g} \cdot \mathrm{L}^{-1}$ & 0.71 \\
\hline $\mathrm{Cu}$ & $\mu \mathrm{g} \cdot \mathrm{L}^{-1}$ & 0.56 \\
\hline $\mathrm{Hg}$ & $\mu \mathrm{g} \cdot \mathrm{L}^{-1}$ & $<0.002$ \\
\hline $\mathrm{Mn}$ & $\mu \mathrm{g} \cdot \mathrm{L}^{-1}$ & 48.4 \\
\hline Mo & $\mu g \cdot L^{-1}$ & 800 \\
\hline $\mathrm{Ni}$ & $\mu \mathrm{g} \cdot \mathrm{L}^{-1}$ & 10 \\
\hline $\mathrm{Pb}$ & $\mu \mathrm{g} \cdot \mathrm{L}^{-1}$ & 0.70 \\
\hline $\mathrm{Si}$ & $\mathrm{mg} \cdot \mathrm{L}^{-1}$ & 7.10 \\
\hline $\mathrm{Sr}$ & $\mu \mathrm{g} \cdot \mathrm{L}^{-1}$ & 1900 \\
\hline $\mathrm{Zn}$ & $\mu g \cdot \mathrm{L}^{-1}$ & 33 \\
\hline V & $\mu \mathrm{g} \cdot \mathrm{L}^{-1}$ & 10.2 \\
\hline B & $\mu \mathrm{g} \cdot \mathrm{L}^{-1}$ & 85.5 \\
\hline Th & $\mu g \cdot \mathrm{L}^{-1}$ & $<0.04$ \\
\hline $\mathrm{U}$ & $\mu \mathrm{g} \cdot \mathrm{L}^{-1}$ & 150 \\
\hline
\end{tabular}

*: Total organic carbon.

A $5 \% \%_{\mathrm{v} / \mathrm{v}} \quad \mathrm{H}_{3} \mathrm{PO}_{4}$ solution was used for the granulation of the powdered DB-12P-HP. The granulation process was performed manually by adding gradually the $\mathrm{H}_{3} \mathrm{PO}_{4}$ solution (approximately $50 \mathrm{~mL}$ ) to a container with the DB-12P-HP system as powder with an amount lower than $50 \mathrm{~g}$. Granules where obtained by shaking the mixture with circular movements until the system was aggregated. The wet granules were sieved in a 3 to $4 \mathrm{~mm}$ mesh and the process was repeated until obtaining a particle size between 3 to $4 \mathrm{~mm}$. It was possible to granulate 400-500 $\mathrm{g}$ of DB-12P-HP per batch with approximately $50 \mathrm{~mL}$ of the $\mathrm{H}_{3} \mathrm{PO}_{4}$ solution. These batches were dried at room temperature followed by a heat treatment of $500{ }^{\circ} \mathrm{C}$ for $4 \mathrm{~h}$ for improving its porosity and further resistance to water flow.

\subsubsection{Sorption Properties}

The specific surface area as $\mathrm{m}^{2} \cdot \mathrm{g}^{-1}$ was measured for DB-12P-HP with the BET method [32] by means of a Gemini $\mathrm{VI}^{\circledR}$ instrument manufactured by Micromeritics USA Ltd. The value obtained was 209 $\mathrm{m}^{2} \cdot \mathrm{g}^{-1}$ for DB-12P-HP.

\subsection{Dynamic Mode Sorption Assembly}

The DB-12P-HP granules were placed inside of a column of $1.5 \mathrm{~cm}$ diameter and $50 \mathrm{~mL}$ capacity. The amount of sorbent was $24 \mathrm{~g}$ for the column and the bulk density was $0.54 \mathrm{~g} \cdot \mathrm{mL}^{-1}$ for DB-12P-HP. An initial regeneration with $0.1 \mathrm{~L}$ of a $7.5 \% \%_{\mathrm{v} / \mathrm{v}} \mathrm{HCl}$ solution was performed prior to the first sorption experiment. The column was then washed with deionized water for removal of the remaining acid. Afterward, the sample was introduced without any $\mathrm{pH}$ adjustment ( $\mathrm{pH} 7.5$ ), from the top of the column at a $Q$ of $3 \mathrm{~mL} \cdot \mathrm{min}^{-1}$ by gravity. The temperature was $10^{\circ} \mathrm{C}$ over the whole sorption experiment. Volume samples were collected from the bottom of the columns. In addition, aliquots of $5 \mathrm{~mL}$ were taken for each of the volumes sampled for quantifying the concentration of $\mathrm{U}^{6+}$ after contact with the sorbent.

After reaching saturation of the sorbent at $\mathrm{pH} 7.5$, a second regeneration was carried out with the $7.5 \%{ }_{\mathrm{v} / \mathrm{v}}$ $\mathrm{HCl}$ solution. Samples were taken during the regeneration in order to determine the amount of acid required for "cleaning" the sorbent. After regeneration and washing with deionized water, the $\mathrm{pH}$ of the sample was adjusted to 4.0 with concentrated $\mathrm{HCl}$ and then a second sorption experiment was performed at the same temperature and $Q$ as the previous one. 
Table 2 XRF data of the DB-12P-HP sorbents.

\begin{tabular}{|c|c|c|c|c|c|c|c|c|c|c|}
\hline \multirow{2}{*}{ Sorbent } & \multicolumn{10}{|c|}{ Element } \\
\hline & $\mathrm{O}$ & $\mathrm{Na}$ & $\mathrm{Mg}$ & $\mathrm{Al}$ & $\mathrm{Si}$ & $P$ & $\mathrm{~K}$ & $\mathrm{Ca}$ & $\mathrm{Ti}$ & $\mathrm{Fe}$ \\
\hline DB-12P-HP & 63.5 & 0.50 & 0.70 & 2.60 & 21.60 & 9.00 & 0.30 & 0.40 & 0.20 & 1.20 \\
\hline
\end{tabular}

\subsection{Analytic Methods}

The analytic methods were performed in accordance to the standard methods for examination of water and wastewater [31]. The $\mathrm{pH}$ of the volumes sampled from the outlet of the columns was measured in a Thermo Orion pH-meter model Dual Star. All the aliquots taken from the volume samples were preserved by adding ultrapure $\mathrm{HNO}_{3}$ to a final concentration of $5 \% \mathrm{v} / \mathrm{v}$ in the samples diluted with Milli-Q water. Thereafter, all the samples were analyzed by ICP (inductively coupled plasma) MS (mass spectrometry) model Agilent Tech. 8800 Triple Squad for the data evaluation and determination of adsorption isotherms (Langmuir and Freundlich). A set of three blanks was analyzed simultaneously with the samples for the estimation of the detection and quantification limits of U-238.

\subsection{Data Evaluation}

The amount of the element adsorbed at equilibrium was calculated with Eq. (1) as follows [33],

$$
q=\frac{\left(c_{0}-c\right) \cdot V}{m}
$$

where, $q$ is the amount of the metal ion adsorbed per unit of mass of the sorbent $\left(\mathrm{mg} \cdot \mathrm{g}^{-1}\right)$ at saturation; $c_{0}$ is the initial concentration $\left(\mathrm{mg} \cdot \mathrm{L}^{-1}\right)$ of the analyte in solution; $c$ is the residual concentration $\left(\mathrm{mg} \cdot \mathrm{L}^{-1}\right)$ of the analyte after contact with the sorbent; $V$ is the volume sampled (L) and $\mathrm{m}$ is the mass of dry sorbent $(\mathrm{g})$.

Two models were utilized in order to assess the experimental sorption isotherms: Langmuir and Freundlich models [34]. The Langmuir approach was selected for the estimation of the maximum adsorption capacity corresponding to the surface of the sorbents as seen from Eq. (2) [33]. Whereas, the Freundlich model was chosen to estimate the adsorption intensity of the metal ion towards the sorbent as shown in Eq. (3) [33].

$$
\frac{1}{q}=\frac{1}{c q_{0} \cdot K_{L}}+\frac{1}{q_{0}}
$$

where, $K_{L}$ is a constant derived from the adsorption/desorption energy $\left(\mathrm{L} \cdot \mathrm{mg}^{-1}\right)$, and $q_{0}$ is the maximum adsorption upon equilibrium or saturation of the surfaces of the sorbent $\left(\mathrm{mg} \cdot \mathrm{g}^{-1}\right)$ [33]. The plot $1 / q$ versus $1 / c$ allows determining these constants.

$$
\log (q)=\log \left(K_{F}\right)+\frac{1}{n} \log (c)
$$

where, $K_{F}$ is known as the Freundlich constant and a measure of the sorption capacity; $n$ is a constant that describes the affinity of the metal towards the surface of the sorbent [33]. The constant $K_{F}$ and $n$ can be calculated from the slope and the intercept of the linear plot of $\log (q)$ versus $\log (c)$ [33].

\section{Results and Discussions}

\subsection{Sorption Experiment}

The effect of the $\mathrm{pH}$ was investigated in order to determine the saturation volume of DB-12P-HP at a $Q$ of $3 \mathrm{~mL} \cdot \mathrm{min}^{-1}$. As seen from Fig. 1, the sorption capacity was significantly decreased by adjusting the $\mathrm{pH}$ of the sample (leachate) to 4 . The sorbent was saturated with approximately $50 \%$ of the volume passed through the column for $\mathrm{pH} 7.5$.

Such behavior can be explained by the species of $\mathrm{U}^{6+}$ in solution and the presence of other inorganic ligands such as sulphate, carbonate and phosphate [23-26]. Moreover, the competition of $\mathrm{U}^{6+}$ for sorption sites with $\mathrm{SO}_{4}{ }^{2-}$ ions (from the alum shale as shown in Table 1) is higher at lower $\mathrm{pH}$ values. Furthermore, the formation of uranyl-sulphate complexes could potentially influence the sorption process as well at values lower than $\mathrm{pH}$ 7.5. This result is in accordance 


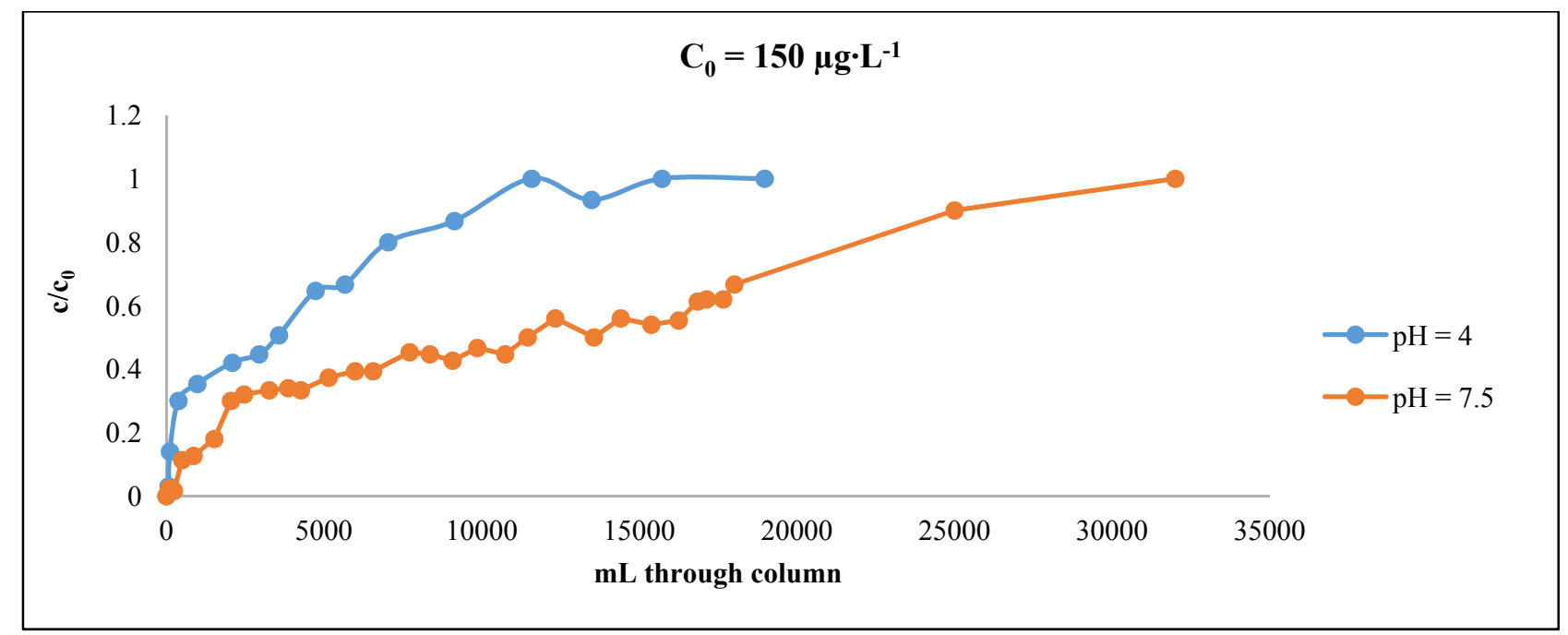

Fig. 1 Saturation curves for $\mathrm{U}^{6+}$ sorption with DB-12P-HP at $10^{\circ} \mathrm{C}$ and $Q=3 \mathrm{~mL} \cdot \mathrm{min}^{-1}$.

with the findings of Bachmaf et al. [35] for a bentonite as a sorbent were the predominant species of $\mathrm{U}^{6+}$ in the solution $\left(0.01 \mathrm{M} \mathrm{NaCl}+0.005 \mathrm{M} \mathrm{Na}_{2} \mathrm{SO}_{4}\right.$ and [U] $\left.=5 \times 10^{-5} \mathrm{M}\right)$ were $\mathrm{UO}_{2} \mathrm{OH}^{+}$and $\left(\mathrm{UO}_{2}\right)_{3}(\mathrm{OH})^{5+}$ for $\mathrm{pH}$ values between 4 and 5 . These hydrolyzed species of $\mathrm{U}$, readily form ligands with the phosphate groups fixated to the surface of DB-12P-HP.

The sorption capacity was determined by means of the fitting of the experimental data into the equilibrium isotherm models of Langmuir and Freundlich. The linearized form of both isotherms is shown in Figs. 2 and 3.

The results of $K_{L}, K_{F}, n$ and $q_{0}$ from the linear

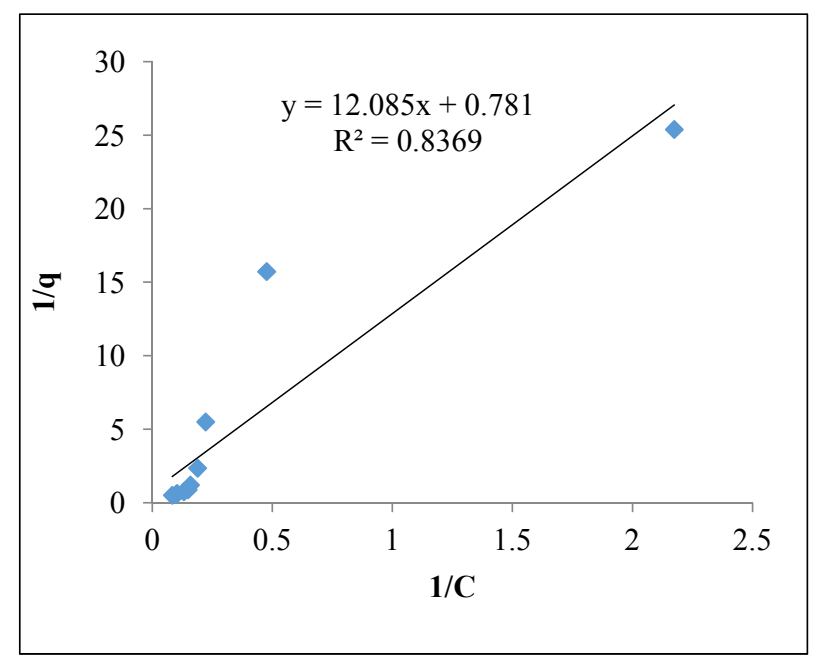

(a) regressions of Fig. 2 and Fig. 3 can be seen from Table 3 along with their correlation coefficients $\left(R^{2}\right)$.

The sorption process is better described in both pH's with the Freundlich isotherm due to the higher $R^{2}$ fitting values. Moreover, there is a substantial difference in magnitude between $\mathrm{pH} 4$ and $\mathrm{pH}$ 7. The latter showing a higher degree of sorption for $\mathrm{U}^{6+}$ with a sorption capacity of $30 \mu \mathrm{g} \cdot \mathrm{g}^{-1}$ compared to $0.6 \mu \mathrm{g} \cdot \mathrm{g}^{-1}$ as seen from Fig. 4 (a) and (b).

The sorption capacity of DB-12P-HP at $\mathrm{pH} 7.5$ is comparable to the one of hydrous lanthanum oxide $\left(38 \mu \mathrm{g} \cdot \mathrm{g}^{-1}\right)$ for $\mathrm{U}$ removal from seawater [36]. Such sorbent represents an alternative to the expensive and

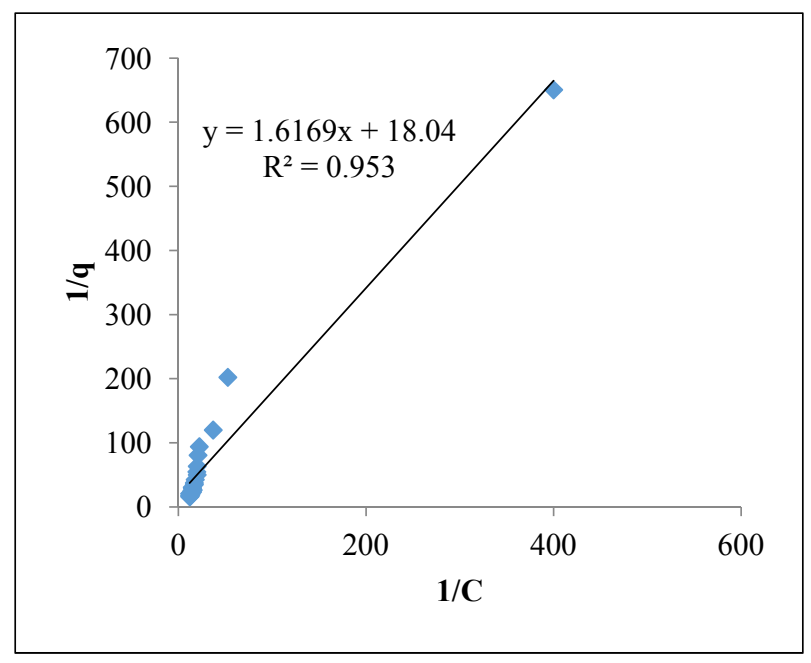

(b)

Fig. 2 Linearized form of the Langmuir isotherm for (a) $\mathrm{pH}=4$ and (b) $\mathrm{pH}=7.5$. 


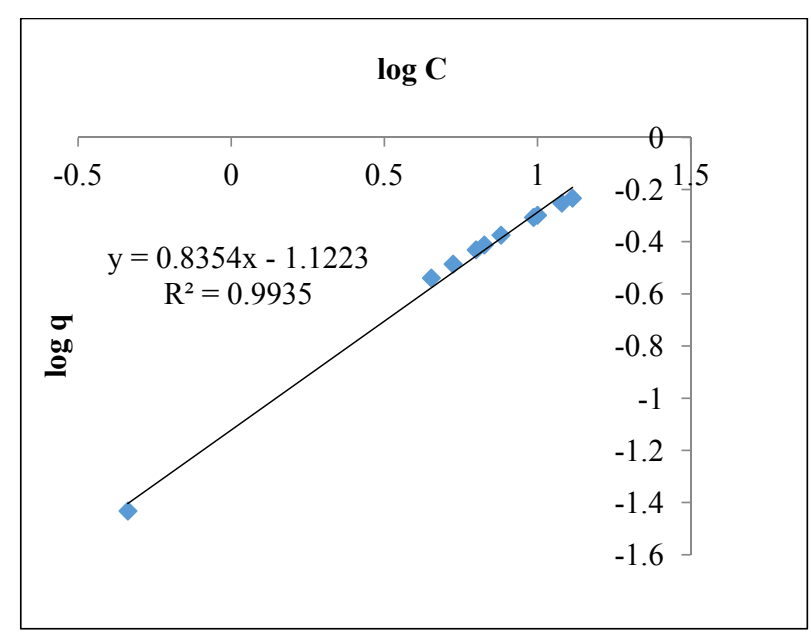

(a)

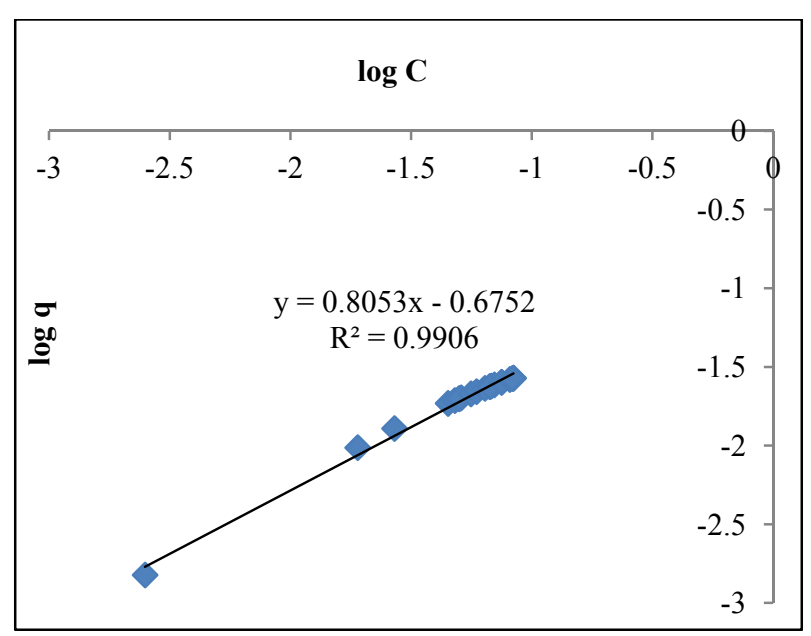

(b)

Fig. 3 Linearized form of the Freundlich isotherm for (a) $\mathrm{pH}=4$ and (b) $\mathrm{pH}=7.5$.

Table 3 Values of the constants of the Langmuir and Freundlich isotherms at the studied pH's.

\begin{tabular}{lllllll}
\hline $\mathrm{pH}$ & \multicolumn{3}{c}{ Langmuir } & \multicolumn{2}{c}{ Freundlich } \\
\cline { 2 - 7 } & $R^{2}$ & $q_{0}$ & $K_{L}$ & $R^{2}$ & $\mathrm{n}$ & $K_{F}$ \\
\hline 4 & 0.8369 & $1.28^{\mathrm{a}}$ & $0.0646^{\mathrm{c}}$ & 0.9935 & 1.1970 & $0.0755^{\mathrm{e}}$ \\
7.5 & 0.953 & $0.055^{\mathrm{b}}$ & $11.16^{\mathrm{d}}$ & 0.9906 & 1.2418 & $0.2113^{\mathrm{f}}$ \\
\hline
\end{tabular}

a. $\mu g \cdot g^{-1}$

${ }^{\mathrm{b}}: \mathrm{mg} \cdot \mathrm{g}^{-1}$

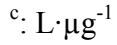

d: $\mathrm{L}^{\mathrm{m}} \mathrm{mg}^{-1}$

e: $\left(\mu \mathrm{g} \cdot \mathrm{L}^{1 / \mathrm{n}}\right) \cdot\left(\mathrm{g} \mu \mathrm{g}^{1 / \mathrm{n}}\right)^{-1}$

f: $\left(\mathrm{mg} \cdot \mathrm{L}^{1 / \mathrm{n}}\right) \cdot\left(\mathrm{g} \cdot \mathrm{mg}^{1 / \mathrm{n}}\right)^{-1}$

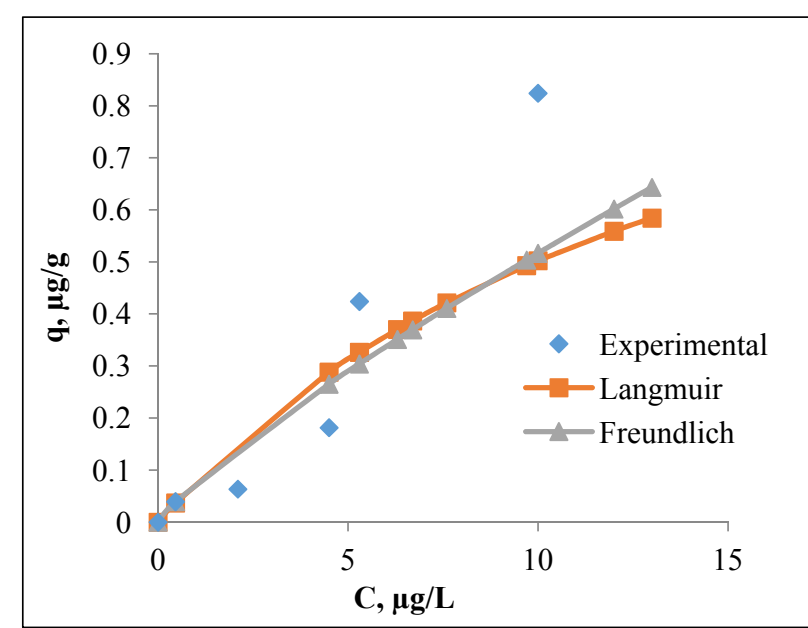

(a)

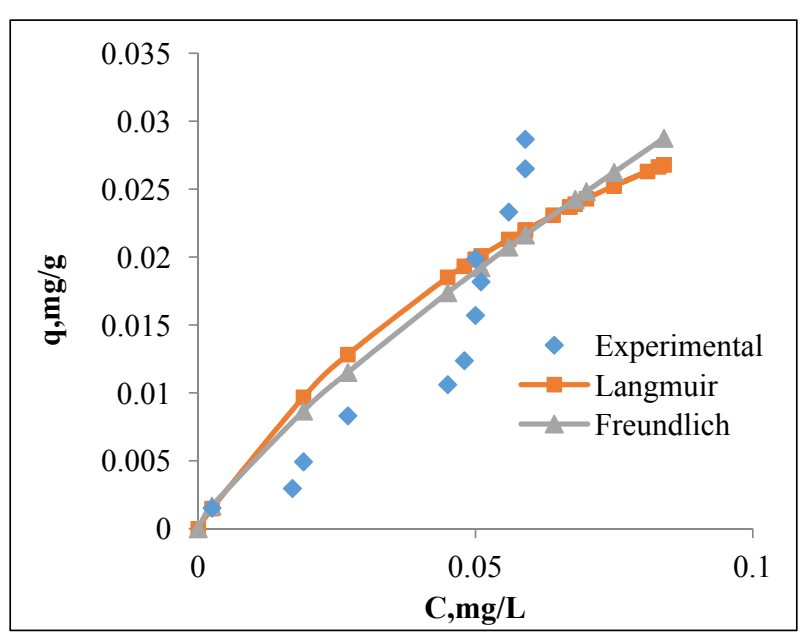

(b)

Fig. 4 Equilibrium isotherms for (a) $\mathrm{pH}=4$ and (b) $\mathrm{pH}=7.5$.

freshly prepared hydrous titanium oxide, with a capacity $1,550 \mu \mathrm{g} \cdot \mathrm{g}^{-1}$ (from sea water as well). Khalili et al. [10] have found $q$-values as high as $62 \mathrm{mg} \cdot \mathrm{g}^{-1}$ for $\mathrm{U}^{6+}$ removal from a synthetic solution of $\mathrm{U}$ and $\mathrm{Th}$ with a bentonite at $\mathrm{pH} 3$ and $\mathrm{T}=25{ }^{\circ} \mathrm{C}$ with a $C_{0}$ of
$100 \mathrm{ppm}$. Such a broad difference in removal capacity from those studies shows clearly the effect of the competition for sorption sites on the surface of the natural bentonites in multicomponent systems as sea water or leachates for instance. 


\subsection{Sorption Mechanism}

The variation of $\mathrm{pH}$ in the columns (at $10{ }^{\circ} \mathrm{C}$ ) suggest that there is a cationic exchange mechanism for DB-12P-HP as seen from Fig. 5 (a) and (b). The leachate before being passed through the column had a $\mathrm{pH}$ 4. The sorption test with $\mathrm{NaCl} 0.1 \mathrm{~N}$ with an initial $\mathrm{pH}$ of 5.5 confirms the type of mechanism. The $\mathrm{pH}$ inside of the column sharply decreases to a value of 2.6 as seen from Fig. 5 (a) due to the production of $\mathrm{H}^{+}$ ions from the cation exchange. It gradually increases and it stabilizes to a value of 4 in the column as seen from Fig. 5 (a) and (b). Moreover, the pH starts to change after $7,000 \mathrm{~mL}$ in Fig. 5 (b) confirming the sorption mechanism. Therefore, the cationic exchange behavior suggests that DB-12P-HP works more

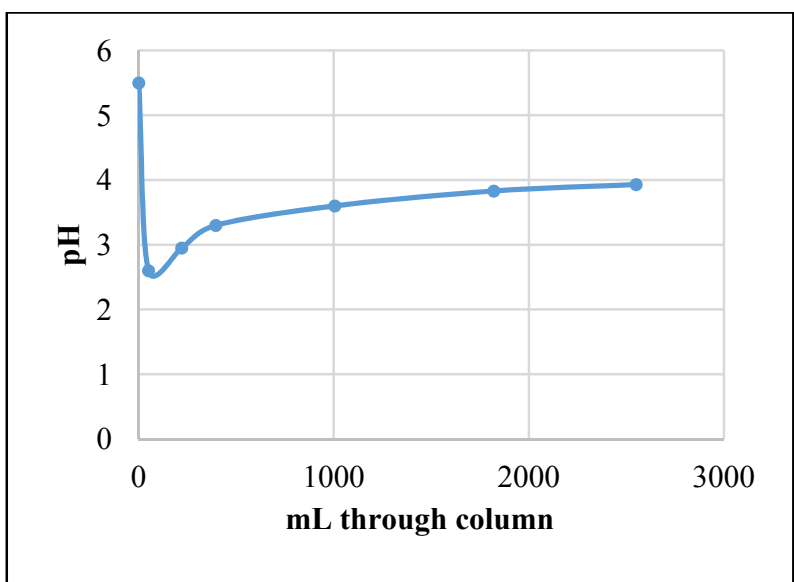

(a) efficiently over $\mathrm{pH} 7$ as seen from the results from the subsection 3.1. A sorbent as DB-12P-HP would hence be more effective for removal of $\mathrm{U}^{6+}$ from alum shale leachate at $\mathrm{pH}$ values higher than 7 due to the cation exchanger nature of the sorption process and the $U$ species in solution.

\subsection{Regeneration Process}

The complete regeneration of the laboratory scale column requires $0.2 \mathrm{~L}$ of $\mathrm{HCl} 7.5 \% \%_{\mathrm{v} / \mathrm{v}}$ as seen from Fig. 6. The desorption process occurs hence at a high rate with a low amount of acid. The power fit of the $\mathrm{U}^{6+}$ desorption shows how rapidly the metal can be concentrated in a small volume of acid. Moreover, the disposal of the regeneration process would be easier due to the low volumes produced by obtaining

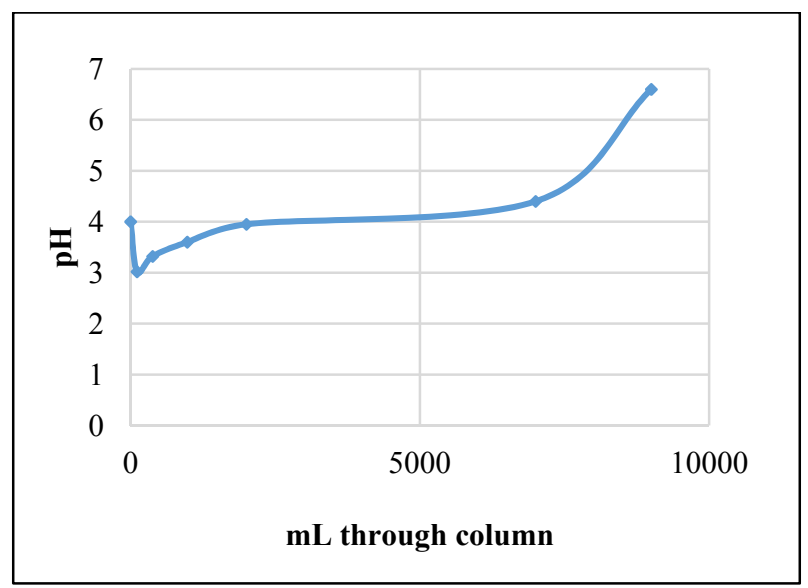

(b)

Fig. $5 \mathrm{pH}$ variation at $10^{\circ} \mathrm{C}$ in the column with (a) $\mathrm{NaCl} 0.1 \mathrm{~N}$ (b) with leachate.

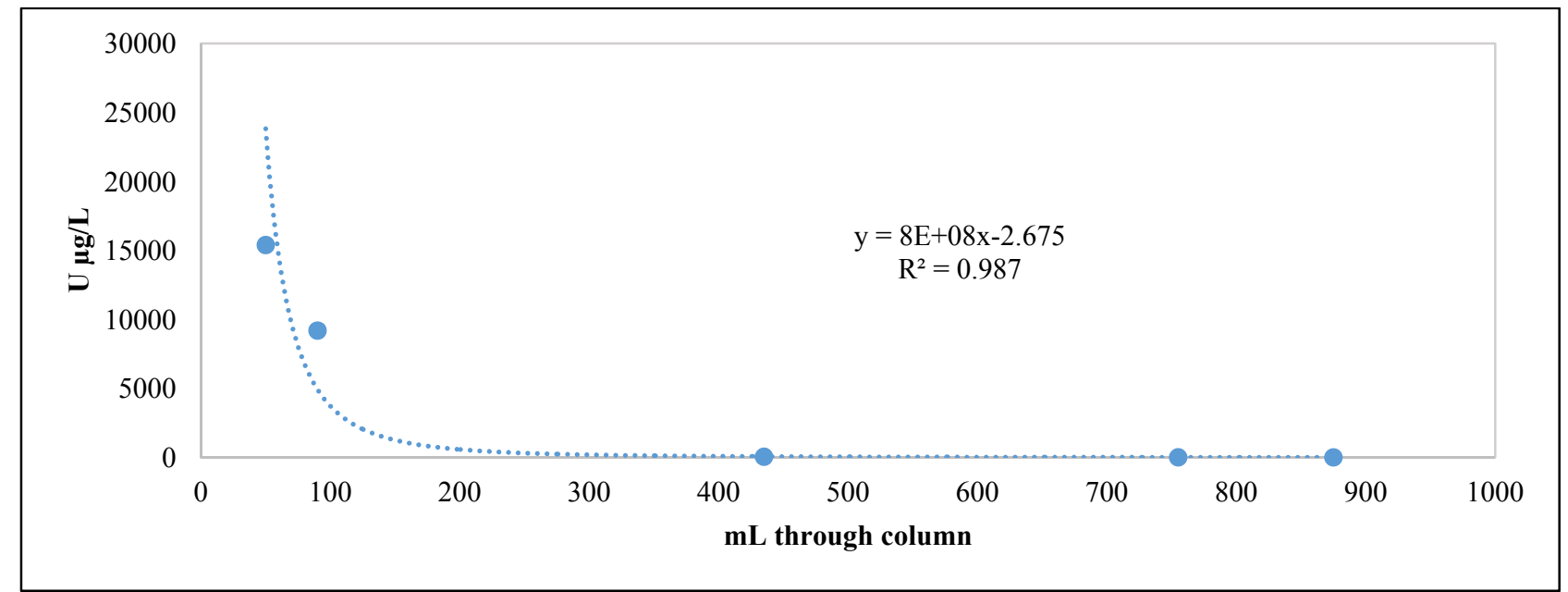

Fig. 6 Desorption of U with $\mathrm{HCl} 7.5 \% \%_{\mathrm{v} / \mathrm{v}}$. 
concentrated solutions of heavy metals, trace elements and radionuclides. The physical sorption of $\mathrm{U}^{6+}$ can therefore be reversed with a significantly low amount and concentration of mineral acid solution. In other words, the regeneration of DB-12P-HP would contribute to a cost effective design of a sorption unit for $\mathrm{U}^{6+}$ in a bigger scale.

\section{Conclusions}

The volume of leachate treated by sorption with DB-12P-HP along with the sorption capacity were drastically decreased by $50 \%$ and around 100 times accordingly at $\mathrm{pH}=4$ in the laboratory scale. This behavior was attributed to the species of $\mathrm{U}^{6+}$ in solution and the high degree of competition for the sites.

The cationic exchange mechanism of DB-12P-HP suggests that the sorption process of $\mathrm{U}^{6+}$ from the alum shale leachate studied is more efficient at $\mathrm{pH}$ values (inside of the column) over 4 .

The regeneration of DB-12P-HP with acids occurs rapidly and with $0.008 \mathrm{~L}$ of $\mathrm{HCl} 7.5 \% \mathrm{v}_{\mathrm{v} / \mathrm{v}}$ per $\mathrm{g}$ of sorbent. It allows to concentrate waste (metals) easily by desorption for the further feasibility estimation and design of an on-site treatment unit.

\section{Acknowledgment}

The authors of this work thank the Norwegian Public Roads Administration (Statens Vegvesen) for the funding of this work through the project "Effects and Environmental Risks Associated to Interventions in Areas with Sulfide Rich Minerals (NORWAT/RV4)".

\section{References}

[1] Jeng, A. S. 1991. "Weathering of Some Norwegian Alum Shales I. Laboratory Simulations to Study Acid Generation and the Release of Sulphate and Metal Cations (Ca, Mg \& K)." Acta Agric. Scand. 41: 13-35.

[2] Kalinowski, B. E., Oskarsson, A., Albinsson, Y., Arlinger, J., Ödegaard-Jensen, A., Andlid, T., and Pedersen, K. 2004. "Microbial Leaching of Uranium and Other Trace Elements from Shale Mine Tailings at Ranstad."
Geoderma 122 (2-4): 177-94.

[3] Andersson, A., and Siman, G. 1991. "Levels of Cd and Some Other Trace Elements in Soils and Crops as Influenced by Lime and Fertilizer Level." Acta Agric. Scand. 41: 3-11.

[4] Jeng, A. S. 1992. "Weathering of Some Norwegian Alum Shales, II. Laboratory Simulations to Study the Influence of Aging, Acidification and Liming on Heavy Metal Release." Acta Agric. Scand. 42: 76-87.

[5] Molochnikova, N. P., Tananaev, I. G., Myasoedova, G. V., and Myasoedov, B. F. 2007. "Sorption Recovery of Radionuclides from Alkaline Solutions Using Fibrous 'Filled' Sorbents." Radiochemistry 49 (1): 64-6.

[6] Zakaria, E. S., Ali, I. M., Aly, H. F., Fuel, N., Dep, T., and Authority, A. E. 2004. "Adsorption Behaviour of 134 Cs and $22 \mathrm{Na}$ Ions on Tin and Titanium Ferrocyanides." 237-44.

[7] Duff, M. C., Hunter, D. B., Hobbs, D. T., Fink, S. D., Dai, Z., and Bradley, J. P. 2004. "Mechanisms of Strontium and Uranium Removal from High-level Radioactive Waste Simulant Solution by the Sorbent Monosodium Titanate." Environ. Sci. Technol. 38 (19): 5201-7.

[8] Gürboga, G., and Tel, H. 2005 "Preparation of $\mathrm{TiO}_{2}-\mathrm{SiO}_{2}$ Mixed Gel Spheres for Strontium Adsorption.” J. Hazard. Mater. 120 (1-3): 135-42.

[9] Lahiri, S., Roy, K., Bhattacharya, S., Maji, S., and Basu, S. 2005. "Separation of $134 \mathrm{Cs}$ and $152 \mathrm{Eu}$ Using Inorganic Ion Exchangers, Zirconium Vanadate and Ceric Vanadate." Appl. Radiat. Isot. 63 (3): 293-7.

[10] Khalili, F. I., Salameh, N. H., and Shaybe, M. M. 2013. "Sorption of Uranium (VI) and Thorium (IV)." by Jordanian Bentonite.

[11] Popa, K. 2013. "Sorption of Uranium on Lead Hydroxyapatite.” J. Radioanal. Nucl. Chem. 298 (3): 1527-32.

[12] Wei, Y., Zhang, L., Shen, L., and Hua, D. 2015. "Positively Charged Phosphonate-Functionalized Mesoporous Silica for Efficient Uranium Sorption from Aqueous Solution.” J. Mol. Liq. In Press, 2015.

[13] Bilgin, B., Atun, G., and Keçeli, G. 2001. "Adsorption of Strontium on Illite." J. Radioanal. Nucl. Chem. 250 (2): 323-8.

[14] Tsai, S. C., Ouyang, S., and Hsu, C. N. 2001. "Sorption and Diffusion Behavior of $\mathrm{Cs}$ and $\mathrm{Sr}$ on Jih-Hsing Bentonite.” Appl. Radiat. Isot. 54 (2): 209-15.

[15] Atun, G., and Kilislioglu, A. 2003. "Adsorption Behavior of Cesium on Montmorillonite-Type Clay in the Presence of Potassium Ions." J. Radioanal. Nucl. Chem. 258 (3): 605-11.

[16] Stout, S. A., Cho, Y., and Komarneni, S. 2006. "Uptake of Cesium and Strontium Cations by Potassium-depleted Phlogopite." Appl. Clay Sci. 31 (3-4): 306-13. 
[17] Turner, G. D., Zachara, J. M., McKinley, J. P., and Smith, S. C. 1996. "Surface-charge Properties and $\mathrm{UO}_{2}{ }^{\dagger} \backslash \mathrm{n} 2$ Adsorption of a Subsurface Smectite." Geochim. Cosmochim. Acta. 60 (18): 3399-414.

[18] Arnold, T., Zorn, T., Bernhard, G., and Nitsche, H. 1998. "Sorption of Uranium(VI) Onto Phyllite." Chem. Geol., 151 (1-4): 129-41.

[19] Baik, M. H., Hyun, S. P., and Hahn, P. S. 2003. "Surface and Bulk Sorption of Uranium ( VI ) Onto Granite Rock." J. Anal. Nucl. Chem. 256 (1): 11-8.

[20] El Aamrani, F. Z., Duro, L., De Pablo, J., and Bruno, J. 2002. "Experimental Study and Modeling of the Sorption of Uranium(VI) onto Olivine-rock." Appl. Geochemistry 17 (4): 399-408.

[21] Gurgel, L. V. A., de Freitas, R. P., and Gil, L. F. 2008. "Adsorption of $\mathrm{Cu}(\mathrm{II}), \mathrm{Cd}(\mathrm{II})$, and $\mathrm{Pb}(\mathrm{II})$ from Aqueous Single Metal Solutions by Sugarcane Bagasse and Mercerized Sugarcane Bagasse Chemically Modified with Succinic Anhydride." Carbohydr. Polym. 74 (4): 922-9.

[22] Mondal, P., Majumder, C. B., and Mohanty, B. 2008. "Effects of Adsorbent Dose, Its Particle Size and Initial Arsenic Concentration on the Removal of Arsenic, Iron and Manganese from Simulated Ground Water by $\mathrm{Fe}^{3+}$ Impregnated Activated Carbon." J. Hazard. Mater. 150 (3): 695-702.

[23] Galindo, C., Del Nero, M., Barillon, R., Halter, E., and Made, B. 2010. "Mechanisms of Uranyl and Phosphate (co)Sorption: Complexation and Precipitation at $\alpha-\mathrm{Al}_{2} \mathrm{O}_{3}$ Surfaces.” J. Colloid Interface Sci. 347 (2): 282-9.

[24] Cheng, T., Barnett, M. O., Roden, E. E., and Zhuang, J. 2004. "Effects of Phosphate on Uranium(VI) Adsorption to Goethite-coated Sand." Environ. Sci. Technol. 38 (22): 6059-65.

[25] Singh, A., Ulrich, K.-U., and Giammar, D. E. 2010. "Impact of Phosphate on U(VI) Immobilization in the Presence of Goethite." Geochim. Cosmochim. Acta 74 (22): 6324-43.

[26] Guo, Z., Li, Y., and Wu, W. 2009. "Sorption of U(VI) on Goethite: Effects of $\mathrm{pH}$, Ionic Strength, Phosphate,
Carbonate and Fulvic Acid.” Appl. Radiat. Isot. 67 (6): 996-1000.

[27] Fox, P. M., Davis, J. A., and Zachara, J. M. 2006. “The Effect of Calcium on Aqueous Uranium(VI) Speciation and Adsorption to Ferrihydrite and Quartz." Geochim. Cosmochim. Acta. 70 (6): 1379-87.

[28] Carvajal, D. A., Katsenovich, Y. P., and Lagos, L. E. 2012. "The Effects of Aqueous Bicarbonate and Calcium Ions on Uranium Biosorption by Arthrobacter G975 strain." Chem. Geol. 330-331 (0): 51-9.

[29] Logue, B. A., Smith, R. W., and Westall, J. C. 2004. "Role of Surface Alteration in Determining the Mobility of U (VI) in the Presence of Citrate: Implications for Extraction of U (VI) from Soils.” Environ. Sci. Technol. 38 (3): 3752-9.

[30] Křepelová, A., Reich, T., Sachs, S., Drebert, J., and Bernhard, G. 2008. "Structural Characterization of U(VI) Surface Complexes on Kaolinite in the Presence of Humic Acid Using EXAFS Spectroscopy.” J. Colloid Interface Sci. 319: 40-7.

[31] APHA. 2012. Standard Methods for the Examination of Water and Wastewater, 22nd ed. American Water Works Association, Clearway Logistics.

[32] Brunauer, S., Emmett, P. H., and Teller, E. "Adsorption of Gases in Multimolecular Layers." J. Amer. Chem. Soc. 60: 309.

[33] Bulgariu, L., Rățoi, M., Bulgariu, D., and Macoveanu, M. 2008. "Equilibrium Study of $\mathrm{Pb}(\mathrm{II})$ and $\mathrm{Hg}(\mathrm{II})$ Sorption from Aqueous Solutions by Moss Peat." Environ. Eng. Manag. J. 7 (5): 511-6.

[34] Bratby, J. 2006. "Colloids and Interfaces." In Coagulation and Flocculation in Water and Wastewater Treatment, 2nd ed. London, UK: IWA Publishing.

[35] Bachmaf, S., Planer-Friedrich, B., and Merkel, B. J. 2008. "Effect of Sulfate, Carbonate, and Phosphate on the Uranium(VI) Sorption Behavior onto Bentonite." Radiochim. Acta 96 (6): 359-66.

[36] Alexandratos, S. D. 2010. "Uranium Separation-Challenges and Opportunities: Recovery of Uranium from Seawater with Solid Sorbents." 